\title{
Airlessgerät für kleinflächige Beschichtungen
}

$F^{u}$ ür kleinflächige Ausbesserungsarbeiten an Schutzbeschichtungen gibt es ein neues akkubetriebenes Airless-Spritzgerät. Die XForceHD Max Power eignet sich außerdem für die Beschichtung von Kleinteilen oder einzelnen Bauteilen wie etwa Muttern, Schrauben und Ventilen sowie Steuerkästen, Türen und Komponenten aus Baustahl. Das Gerät erzeugt schnell ein einschichtiges Finish. Es ersetzt die mühevolle Beschichtung mit Bürsten und Rollen, bei denen oftmals mehrere Schichten aufgetragen werden müssen. Ein weiterer Vorteil besteht darin, dass fortan keine großen Airlessgeräte mehr befüllt werden müssen, wenn lediglich eine kleine Fläche gespritzt werden soll. Das Gerät ist für verschiedene Schutzbeschichtungen und Korrosionsschutzmaterialien geeignet, etwa Beschichtungen auf Lösemittel- und Wasserbasis, Decklacke für Polyurethan-Beschichtungen mit hohem Feststoffgehalt, feuerhemmende Beschichtungen oder Mehrkomponentenbeschichtungen.

Tel. 003289 770700, www.graco.com

\section{Vielseitiges und sparsames Rotationsstrahlgerät}

$M$ it ihrem neuen Rotationsstrahlgerät hat die Firma Fastje ein modulares System entwickelt, das sich mit diversen Elementen wie Dosier- und Absperrventilen an verschiedene Anwendungen anpassen lässt. Gestrahlt werden können Metall, Glas und Stein, Kunststoffe

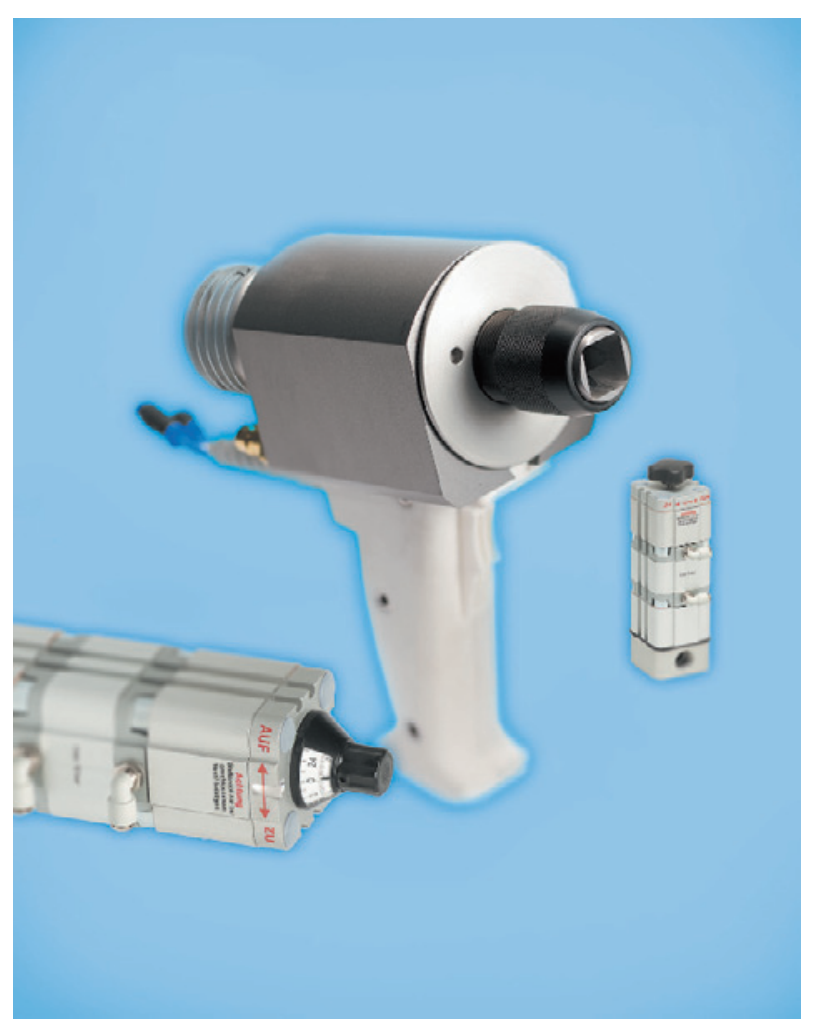

oder Holz. Das Gerät eignet sich für kraftvolles oder sanftes, trockenes oder feuchtes Strahlen. Die Rotationsdrehzahl lässt sich stufenlos zwischen 100 und $5.700 \mathrm{l} / \mathrm{min}$ einstellen. Die ausströmende Druckluft bläst das Strahlmittel gleichmäßig aus, sodass ein Strahlbild ohne Schattierungen entsteht. Dazu tragen auch die Rotationsbewegungen der Strahlwelle und Strahldüse bei, die das Strahlmittel und die Strahlenergie einheitlich verteilen. Die Dosierund Absperrventile des Strahlgerätes sorgen für eine fein geregelte Zufuhr. Sie eignen sich für Metalle, Mineralien, Pulver und organische Stoffe sowie für Pasten und Flüssigkeiten. Weitere Vorteile des Geräts sind der reduzierte LuftEnergie- und Strahlmittelverbrauch.

Tel. 0711 78238552, helmut.fastje@gmx.de

\section{Online-Kalkulator} für Kartonagen

$D^{i}$ e Firma Nordpack GmbH hat jetzt zusätzlich zum Vertriebsaußendienst ihren neuen elektronischen Vertriebsweg im Internet eröffnet. Angeboten werden dort Standardartikel aus der Verpackungsbranche für den Versand eines Produktes per Paket oder auf Palette. Eine Besonderheit ist der Online-Kalkulator für Kartonagen, mit dem der Kunde schnell die richtige Größe oder Dicke der gewünschten Kartons ermitteln kann. Alle Produkte werden in verschiedene Navigationskategorien unterteilt. Mit der Suchfunktion kann der Kunde gezielt auf 5.000 Artikel zugreifen. Darüber hinaus kann der Kunde seine Bestellungen bündeln. So ist es möglich, einen BMEcat-Katalog mit eCl@ss, einem Klassifikationssystem für Warengruppen, zu erstellen. Das System verfügt dafür über verschiedene Schnittstellen für diverse Anwendungen. Darüber hinaus bietet das Portal viele Anwendungs-Videos, in denen die einzelnen Verpackungsmaterialien vorgestellt werden.

www.nordpack24.de

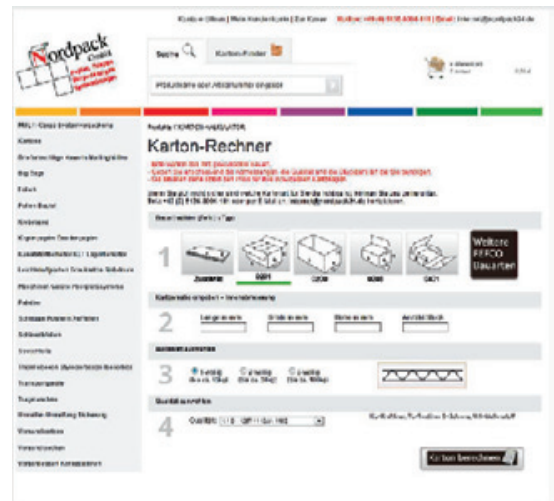

